\title{
Career preferences of graduating medical students in China: a nationwide cross- sectional study
}

\author{
Jianlin Hou ${ }^{1 \dagger}$, Maoyi Xu ${ }^{2 \dagger}$, Joseph C. Kolars ${ }^{3}$, Zhe Dong ${ }^{1}$, Weimin Wang ${ }^{4}$, Amy Huang ${ }^{3}$ and Yang Ke ${ }^{4 *}$
}

\begin{abstract}
Background: China faces major challenges in the distribution of health professionals with serious shortages in rural areas and in the development of Primary Care Providers (PCPs). This study investigates the career preferences of medical students in China and the impact of rural backgrounds on these preferences.

Methods: Medical students in the final year of their program in 16 medical schools across China completed a 58-item survey that included questions regarding their demographic characteristics, attitudes toward practice in low resource areas, postgraduate planning, self-assessed competency, university facilities assessment, and financial situation. Descriptive calculation and Logit model were used for the analysis.

Results: Completed surveys from 3020 students were included in the analysis. Upon graduation, $48.5 \%$ of the medical students preferred to work in urban public hospitals and this percentage rose to $73.6 \%$ when students were asked to state their anticipated preference five years after graduation. Students' top three ranked reasons for preferred careers were "good career prospects", "living close to parents/families", and "remuneration". Those who preferred to work in rural areas upon graduation were more likely to be those who lived in rural areas when 1-15 years old $(\beta=2.05, p<0.001)$, had high school in rural areas $(\beta=1.73, p<0.001)$, or had parents' place of current residence in rural areas $(\beta=2.12, p<0.001)$. Similar results were found for those students who preferred to work in PCPS.

Conclusions: To address the serious shortages of health professionals in rural areas and PCPs, medical schools should consider strategies to recruit more medical applicants with rural backgrounds and to orient students to rural and primary care interests.
\end{abstract}

Keywords: Career preference, Graduating medical students, Rural health workforce, Primary care provider, China

\section{Background}

China faces major challenges in the distribution of health professionals throughout the country. Urban hospitals attract most of the health professionals with serious shortages in rural areas where approximately $50 \%$ (642 million) of the population currently resides. In 2012, the following gaps were observed between rural and urban areas for health professionals (3.41 VS 8.55), doctors (1.00 VS 2.96), registered nurses (RNs) (1.09 VS 3.65) per 1000 population [1]. Compared to physicians

\footnotetext{
* Correspondence: keyang@bjmu.edu.cn

${ }^{\dagger}$ Equal contributors

${ }^{4}$ Peking University Health Science Center, Beijing 100191, China

Full list of author information is available at the end of the article
}

in urban areas, doctors in rural areas were characterized as having lower levels of educational level, professional knowledge, and competency [2,3]. In township health centers, which serve as the focus of care in rural settings, less than $50 \%$ of physicians and physician assistants had an educational level beyond secondary school. The inadequacy in the number and professional capabilities of health professionals in rural areas contributes to decreased access to health care for rural residents, relative to their urban counterparts [4].

Urban hospitals often define themselves as referral centers that focus on secondary or tertiary care. Primary health care has been relatively under-developed but more recently identified as one of three key principles 
for healthcare reform in China, because it plays an increasingly important role in promoting population health, addressing chronic diseases, and reducing health expenditures $[5,6]$. In order to guarantee the availability of primary health care, properly trained health professionals must be appropriately distributed in order to serve the entire population. Nevertheless, reports across China consistently show that shortage of health professionals is one of the most frequently cited issues that threatens the survival and development of primary care providers (PCPs) [7-11].

Despite problems regarding the distribution of health professionals to rural areas and the need for expertise in primary care, the number of newly employed health workers accounted for only $20-40 \%$ of graduates between 2004 to 2008 [12]. Many graduates seek employment in fields outside of healthcare [13]. This indicates an inefficiency of the governments' educational investments to increase the healthcare workforce which, if corrected, could potentially enhance the distribution of healthcare professionals.

Similarly, few medical students choose to focus their careers in underserved areas or in primary care $[14,15]$. It was reported in one survey that about $73 \%$ of students $(n=700)$ in a 3-year medical curriculum preferred to work in urban big-sized hospitals [16]. Data from another medical school shows that the percentage of graduates entering primary care was noted to be decreasing (i.e. $26 \%$ in 2009, $23 \%$ in 2010, and $21 \%$ in 2011) [17].

To address the lack of interest in primary care or in rural practice, it is important to understand the career preferences of medical students and variables that influence these choices. Research to date has been limited because of small sample size, convenience sampling, confounding factors, and single institution studies [18-21].

The purpose of this study is to understand the career preferences of a multi-institutional sampling of medical students in China. We hypothesize that medical students who come from rural backgrounds are more likely to work in rural areas and pursue careers in primary care practice than those from more urban backgrounds.

\section{Methods}

\section{Participants and procedures}

Undergraduate medical students at 16 medical schools across China are the focus of this study. Thirteen of the sample medical schools were selected by stratified sampling from the 180 undergraduate medical programs in China. Stratification considered location, ownership (public or private), and designation as a Project 211 university (i.e. one of the 112 key universities selected by the Ministry of Education to receive prioritized funding for a series of education reforms since 1995 [22]). Two leaders with expertise in medical education reviewed the sample cohort and a suggestion was made to add another three leading universities (also Project 211 universities) bringing the final number of sample schools to 16 . Four of the sample schools are owned by Project 211 universities. Five, eight, and three of them are located in eastern, middle, and western China, respectively. At each of these medical schools, hard copies of the questionnaire were distributed to all students in their final year of the medical program (year 2012) and collected anonymously, most typically at the end of one of their mandatory lectures.

\section{Ethical considerations}

The study was granted an exemption from requiring ethics approval by Peking University Institutional Review Board because the survey was anonymous and did not include sensitive questions. An introduction about the survey was provided on the first page of the questionnaire, including aims and main contents of the survey, promise to keep the data anonymous and confidential. Participation in the study was voluntary and consent was sought from all participants.

\section{Questionnaire}

The tool used in this study is a self-administered questionnaire that was originally developed in a 5-country project aiming to conduct a situation analysis of health professional education in participating countries. The questionnaire was translated into Chinese and modified for this study in order to better reflect the situation in China.

The modified questionnaire asked information regarding the following seven aspects: demographic characteristics, attitudes toward practice in low resource areas, postgraduate planning, self-assessed competency, university facilities assessment, and financial situation of students and their families. It consisted of 15 fixed response questions, four open-ended items, 39 five-point Likert scale items. The modified questionnaire was pre-tested in a pilot study with students at Peking University Health Science Center.

\section{Analysis}

Descriptive analyses of students' responses include calculation of percentages, means, and standard deviations. Chi-square tests were conducted to compare participants' preferences regarding working in rural areas/PCPs by rural background: whether lived in rural areas when 1-15 years old, whether graduated from a high school in rural areas, or whether his/her parents' place of residence was in rural areas.

Furthermore, Logit models were estimated using Maximum Likelihood Estimation (MLE) techniques to 
Table 1 Summary statistics for graduating medical undergraduates in the study $(N=3020)$

\begin{tabular}{|c|c|}
\hline Variable & Percent or Mean (SD) \\
\hline Age & $23.9(1.1)$ \\
\hline Family income (Yuan) per capita per year & 26718.4(80979.5) \\
\hline \multicolumn{2}{|l|}{ Sex } \\
\hline Male & $44.1 \%$ \\
\hline Female & $55.9 \%$ \\
\hline \multicolumn{2}{|l|}{ Type of medical school } \\
\hline Project 211 university & $6.5 \%$ \\
\hline Non-Project 211 university & $93.5 \%$ \\
\hline \multicolumn{2}{|l|}{ Region } \\
\hline Eastern China & $30.1 \%$ \\
\hline Middle China & $66.1 \%$ \\
\hline Western China & $3.8 \%$ \\
\hline \multicolumn{2}{|l|}{ Father's education } \\
\hline Never attended school & $1.0 \%$ \\
\hline Primary school & $9.7 \%$ \\
\hline High school & $48.2 \%$ \\
\hline Secondary school & $10.1 \%$ \\
\hline Bachelor or diploma & $27.1 \%$ \\
\hline Master & $1.8 \%$ \\
\hline Doctor & $1.1 \%$ \\
\hline Other & $1.2 \%$ \\
\hline \multicolumn{2}{|l|}{ Mother's education } \\
\hline Never attended school & $3.4 \%$ \\
\hline Primary school & $17.6 \%$ \\
\hline High school & $45.5 \%$ \\
\hline Secondary school & $10.4 \%$ \\
\hline Bachelor or diploma & $19.9 \%$ \\
\hline Master & $1.4 \%$ \\
\hline Doctor & $0.8 \%$ \\
\hline Other & $0.8 \%$ \\
\hline \multicolumn{2}{|l|}{ Majority of residence in first years } \\
\hline Town or village & $49.2 \%$ \\
\hline County & $25.4 \%$ \\
\hline City & $24.9 \%$ \\
\hline Other & $0.5 \%$ \\
\hline \multicolumn{2}{|l|}{ Location of high school } \\
\hline Town or village & $10.3 \%$ \\
\hline County & $58.6 \%$ \\
\hline City & $30.2 \%$ \\
\hline Other & $0.9 \%$ \\
\hline
\end{tabular}

Table 1 Summary statistics for graduating medical undergraduates in the study $(N=3020)$ (Continued)

Parents' place of residence

\begin{tabular}{ll} 
Town or village & $43.6 \%$ \\
County & $27.3 \%$ \\
City & $28.2 \%$ \\
Other & $1.0 \%$ \\
\hline
\end{tabular}

explore the factors predicting students' preferences regarding working in rural areas/PCPs. The Logit model was defined as follows:

$$
\begin{aligned}
& \operatorname{Pr}\left(y_{i}=0\right)=\frac{1}{1+\exp \left(X_{i} \beta+\mu_{i}\right)} \\
& \operatorname{Pr}\left(y_{i}=1\right)=\frac{\exp \left(X_{i} \beta+\mu_{i}\right)}{1+\exp \left(X_{i} \beta+\mu_{i}\right)}
\end{aligned}
$$

where $X$ was the vector of explanatory variables, $\mu_{i}$ were unobserved group effects, and the $\beta$ were parameters to be estimated.

\section{Dependent variables}

Dependent variables in the Logit model were students' preference regarding working in rural areas/PCPs upon graduation ('yes' or 'no'). Rural areas were defined as being located in a county, town, or village [23].

\section{Independent variables}

For each of the dependent variables, three key independent variables were entered into the model, namely whether students lived in rural areas when 1-15 years old, whether students' high school was located in a rural area, and whether his/her parents' place of residence was in a rural area. Other controlling independent variables included age, sex, father's education, mother's education, family income per capita per year in the past five years, type of medical school, and region.

All analyses were conducted using StataMP11.0. P value was set at 0.05 to indicate significant differences.

\section{Results}

\section{Descriptive statistics}

Altogether 3052 responses were received, of which 32 ones with missing values were excluded from analysis. As noted in Table 1, the participants' mean age was 24 years. The family income per capita per year in the past five years was 26718.4 Yuan (about US\$ 4312.3). More than half of the participants were female and less than $7 \%$ were from a Project 211 University.

Almost half of the respondents' mother or father had an educational level limited to high school. A substantial proportion of the students lived in towns or villages 
when 1 to 15 years old, had high school located in counties, and had parents living in towns or villages.

Almost half of respondents (48.5\%) preferred to work in urban public hospitals upon graduation. This proportion rose to $73.6 \%$ when students were asked to state their anticipated preference five years after graduation. Other chosen preferences upon graduation were pursuing graduate study (37.6\%), public primary care provider $(8.1 \%)$ and private hospital/clinic $(2.9 \%)$. The remaining preferences upon graduation accounted for less than $1 \%$, including academic employment, going abroad, being self-employed, medical or pharmaceutical company, and non-governmental organization (Table 2). Male respondents' career preferences were different from female ones, such as public hospital (53.1 \% VS $44.8 \%$ ), pursuing graduate study (33.1 \% VS $41.1 \%$ ) (Additional file 1). Furthermore, $71.8 \%$ of the medical undergraduates preferred to work in cities. In contrast, only $23.8 \%$ preferred to work in counties and $2.7 \%$ preferred to work in towns or villages.

As shown in Table 3, the top three ranked reasons for preferred careers were "good career prospects", "living close to parents/families", and "remuneration". Furthermore, the top ranked reason by male and female respondents was "remuneration" and "good career prospects", respectively (Additional file 2 ).

\section{Inferential statistics}

According to results from Chi-square tests (Table 4), it seems that there is a relationship between preference for working in rural areas/PCPs and rural background.

Table 2 Graduating medical undergraduates' career preference

\begin{tabular}{lcc} 
(\%) & & \\
\hline Preferred career & $\begin{array}{c}\text { Upon graduation } \\
(n=3020)\end{array}$ & $\begin{array}{c}\text { Five years after graduation } \\
(n=3020)\end{array}$ \\
\hline Public hospital & 48.5 & 73.6 \\
Pursuing graduate study & 37.6 & 8.1 \\
Public primary care & 8.1 & 7.0 \\
provider & & \\
Private hospital/clinic & 2.9 & 2.1 \\
Academic employment & 0.7 & 2.2 \\
Going abroad & 0.6 & 2.5 \\
Self-employed & 0.4 & 1.9 \\
Medical/pharmaceutical & 0.3 & 0.6 \\
company & & 0.4 \\
Non-governmental & 0.3 & 1.7 \\
organization & & 100.0 \\
Other & 0.8 & \\
Total & 100.0 & \\
\hline
\end{tabular}

Table 3 Reasons for preferred career (\%)

\begin{tabular}{lccc}
\hline Reasons & $\begin{array}{c}1^{\text {st }} \\
(n=2,706)\end{array}$ & $\begin{array}{c}2^{\text {nd }} \\
(n=2,685)\end{array}$ & $\begin{array}{r}3^{\text {rd }} \text { reason } \\
(n=2,678)\end{array}$ \\
\hline Good career prospects & 29.1 & 17.0 & 15.3 \\
Living close to parents/families & 26.9 & 17.7 & 11.5 \\
Remuneration & 20.8 & 20.6 & 18.5 \\
Nice place to live & 5.8 & 10.7 & 11.3 \\
Return to hometown & 4.6 & 7.2 & 5.2 \\
Social prestige & 3.2 & 4.9 & 7.8 \\
Work environment & 3.1 & 7.1 & 11.9 \\
Opportunity for further training & 2.9 & 7.2 & 6.6 \\
Get away from parents & 2.3 & 3.0 & 1.3 \\
Good welfare & 0.9 & 3.5 & 7.5 \\
Housing & 0.3 & 0.9 & 2.7 \\
Other & 0.4 & 0.2 & 0.3 \\
Total & 100.0 & 100.0 & 100.0 \\
\hline
\end{tabular}

\section{Logit models}

Table 5 presented summary results of the six Logit models (detailed results are listed in Additional file 3, Additional file 4, Additional file 5, Additional file 6, Additional file 7 and Additional file 8).

Medical students who preferred to work in rural areas upon graduation were more likely to be those lived in rural areas when $1-15$ years old $(\beta=2.05, \mathrm{p}<0.001)$ (Model 1), had high school in rural areas $(\beta=1.73$, $\mathrm{p}<0.001$ ) (Model 2), and had parents' place of current residence in rural areas $(\beta=2.12, \mathrm{p}<0.001)$ (Model 3). Similarly, medical students who prefer to work in PCPs were more likely to be those lived in rural areas when $1-15$ years old $(\beta=0.85, \mathrm{p}<0.01)$ (Model 4), had high school in rural areas $(\beta=0.51$, $\mathrm{p}<0.05$ ) (Model 5), and had parents' place of residence in rural areas $(\beta=0.68, \mathrm{p}<0.01)$ (Model 6).

\section{Discussion}

This study provides rich information regarding medical students' career preferences, reasons for their career choices, and the relationship between rural background with preference for rural and PCP employment. By collecting data from multiple institutions across China, this study contributes to the literature by improving the generalizability of findings.

We found that medical undergraduates mainly preferred to work in public hospitals or pursue graduate study. Students who pursue graduate study do so in public hospitals where they are exposed to employment possibilities. Therefore the percentage of public hospital preference should be more than reported in this study. Consistent with previous findings, this study found that only a minority of medical students preferred to work in 
Table 4 Preference for rural areas and PCPs by past experiences in rural areas

\begin{tabular}{|c|c|c|c|c|c|c|}
\hline & \multicolumn{2}{|c|}{$\begin{array}{l}\text { Preference for practice in rural areas } \\
\text { upon graduation }\end{array}$} & \multirow[t]{2}{*}{ Chi-square } & \multicolumn{2}{|c|}{$\begin{array}{l}\text { Preference for public PCP } \\
\text { upon graduation }\end{array}$} & \multirow[t]{2}{*}{ Chi-square } \\
\hline & $\begin{array}{l}\text { Yes } n=803 \\
(26.6 \%)\end{array}$ & $\begin{array}{l}\text { No } n=2,217 \\
(73.4 \%)\end{array}$ & & $\begin{array}{l}\text { Yes } n=244 \\
(8.1 \%)\end{array}$ & $\begin{array}{l}\text { No } n=2,776 \\
(91.9 \%)\end{array}$ & \\
\hline Residence in rural areas when $1-15$ years old & & & $234.80^{* * *}$ & & & $28.78^{* * *}$ \\
\hline Yes & $761(94.8)$ & $1,492(67.3)$ & & 217(88.9) & 2,036(73.3) & \\
\hline No & $42(5.2)$ & $725(32.7)$ & & $27(11.1)$ & $740(26.7)$ & \\
\hline High school located in rural areas & & & $252.17^{* * *}$ & & & $21.04^{* * *}$ \\
\hline Yes & 732(91.2) & $1,350(60.9)$ & & 200(82.0) & $1,882(67.8)$ & \\
\hline No & $71(8.8)$ & $867(39.1)$ & & $44(18.0)$ & 894(32.2) & \\
\hline Parents current residence in rural areas & & & $281.14^{* * *}$ & & & $25.11^{* * *}$ \\
\hline Yes & 754(93.9) & $1,386(62.5)$ & & 207(84.8) & $1,933(69.6)$ & \\
\hline No & $49(6.1)$ & $831(37.5)$ & & $37(15.2)$ & $843(30.4)$ & \\
\hline
\end{tabular}

Note: (1) Percentage in parenthesis; $(2) * * *$ statistically significant at the 1 percent level

rural areas and PCPs $[14,15,24]$. Reasons for not seeking employment in rural areas/PCPs were lack of opportunities for professional development and potential for job promotion, social connection with life in cities, and satisfactory reward [25-28]. Our study also found that main factors influencing medical undergraduate' career choices are career prospects, geographic location, and remuneration. By comparison, reports from developed countries on barriers to work in rural areas include poor working conditions, low job satisfaction, political problems, ethical problems, and poor security $[29,30]$. Factors predisposing medical undergraduates to work in rural vs. urban areas are likely context-specific.

We found rural students are more likely to prefer to work in rural areas and in PCPs. Again, these findings correspond well to findings from relevant research in China [17, 31-33] and other countries [34-37]: rural exposure is positively associated with subsequent practice in rural areas and in PCPs. Students with rural backgrounds presumably have more real contact with rural population, and are more aware of the gap between their health needs and the access to health care. Exposure to the hardship regarding health access of underserved people in rural areas may help to establish internal empathy and balance out the appreciation of good rewards and promising career prospects. Medical students with rural background may found it easier to fit into the rural environment.

This study has several implications. First, schemes to increase the number of health professionals in rural and PCPs should start with recruiting medical applicants with rural backgrounds. However, the current admission process of medical schools, with emphasis mainly on academic performances, tends to put rural students in a disadvantaged position. For example, autonomous admission and directly admission of excellent high school students may favor financially advantaged students who are more likely to be from cities with more access to

Table 5 Summary Results of Logit Model Estimations

\begin{tabular}{|c|c|c|c|c|c|c|}
\hline & Logit Model 1 & Logit Model 2 & Logit Model 3 & Logit Model 4 & Logit Model 5 & Logit Model 6 \\
\hline Dependent variable & \multicolumn{3}{|c|}{ Preference for employment in rural areas } & \multicolumn{3}{|c|}{ Preference for employment in public PCPs } \\
\hline Key independent variable & $\begin{array}{l}\text { Residence in rural } \\
\text { areas when 1-15 } \\
\text { years old }\end{array}$ & $\begin{array}{l}\text { High school } \\
\text { in rural areas }\end{array}$ & $\begin{array}{l}\text { Parents' current } \\
\text { residence in } \\
\text { rural areas }\end{array}$ & $\begin{array}{l}\text { Residence in rural } \\
\text { areas when 1-15 } \\
\text { years old }\end{array}$ & $\begin{array}{l}\text { High school } \\
\text { in rural } \\
\text { areas }\end{array}$ & $\begin{array}{l}\text { Parents' current } \\
\text { residence in } \\
\text { rural areas }\end{array}$ \\
\hline$\beta$ & 2.046 & 1.730 & 2.124 & 0.849 & 0.512 & 0.683 \\
\hline Robust standard error & 0.181 & 0.148 & 0.171 & 0.245 & 0.198 & 0.213 \\
\hline$z$ & 11.260 & 11.670 & 12.450 & 3.460 & 2.580 & 3.210 \\
\hline$p$ & 0.000 & 0.000 & 0.000 & 0.001 & 0.010 & 0.001 \\
\hline N & 3020 & 3020 & 3020 & 3020 & 3020 & 3020 \\
\hline Log pseudo likelihood & -1566.388 & -1566.027 & -1540.058 & -806.748 & -810.765 & -808.347 \\
\hline Waldx ${ }^{2}(22)$ & 247.730 & 285.020 & 270.280 & 74.220 & 64.770 & 70.290 \\
\hline Prob $>x^{2}$ & 0.000 & 0.000 & 0.000 & 0.000 & 0.000 & 0.000 \\
\hline Pseudo $R^{2}$ & 0.104 & 0.105 & 0.120 & 0.048 & 0.044 & 0.047 \\
\hline
\end{tabular}


resources for academic preparation. It is worth noting that targeted enrollment of rural students has been implemented by the government to provide health professionals for township health centers in middle and western China [38]. Second, in guiding medical students' career planning, medical schools should present a sense of duty to the needs of the population, many of whom reside in more rural settings. Third, medical schools should orient students to rural and primary care interests by more innovative strategies, such as providing rural replacement or volunteer opportunities to work in rural health services/PCPs, or emphasizing rural health, primary health care, and medical professionalism as components in formal curriculum.

This study has a few limitations. First, the randomness and representative of the data may be threatened because sampled private medical schools did not participated in the survey and the stratification sampling did not take into account some potentially important characteristics variables because they were not released or collected, such as student body demographics and origins and exposure to rural and urban medicine. Hence, the Logit models may be biased and inconsistent due to selection bias. Nevertheless, public medical schools are dominant in China. Data in 2012 demonstrate that private medical schools account only for $16.4 \%$ of all Chinese medical schools. Therefore the influence of not including private medical schools is minor. Second, not all the factors that may play a role in affecting medical undergraduates' preference for working in rural areas or PCPs were included into the models, such as health and income policies. As a result, the Logit model may suffer from omitted variable bias and the coefficients may be lowered. Third, the survey was modified from an international instrument that is used to understand career preferences in other settings. Some of the questions were high-inference and open to interpretation by the respondents. Fourth, the process of conducting the questionnaires at each medical school varied and the return rates were not determined. Therefore, potential bias cannot be fully analyzed.

\section{Conclusions}

By conducting a nationwide questionnaire survey of graduating medical students, we mapped their career preferences, described reasons for the preferences, and found that rural background was associated with preferences for working in rural areas/PCPs. The study results provide insightful implications for policy-making in medical education, including student admission, student career planning, and reforms in medical education.

\section{Consent for publication}

Not applicable.

\section{Available of data and materials}

The dataset on which the conclusions of the manuscript rely is presented in additional supporting files.

\section{Additional files} Additional file 1: Graduating Medical Undergraduates' Career Preferences
by Gender (DOCX $15 \mathrm{~kb}$ )

Additional file 2: Reasons for Preferred Career by Gender (DOCX 16 kb)

Additional file 3: Results of Logit Model 1 Estimation: predicting medical undergraduates' willingness to work in rural areas $(N=3020)$ (DOCX $17 \mathrm{~kb}$ )

Additional file 4: Results of Logit Model 2 Estimation: predicting medical undergraduates' willingness to work in rural areas $(N=3020)$ (DOCX $17 \mathrm{~kb}$ )

Additional file 5: Results of Logit Model 3 Estimation: predicting medical undergraduates' willingness to work in rural areas $(N=3020)$ (DOCX $17 \mathrm{~kb}$ )

Additional file 6: Results of Logit Model 4 Estimation: predicting medical undergraduates willingness' to work in PCPs ( $N=3020)$ (DOCX 17 kb)

Additional file 7: Results of Logit Model 5 Estimation: predicting medical undergraduates' willingness to work in PCPs ( $N=3020)(D O C X 17$ kb)

Additional file 8: Results of Logit Model 6 Estimation: predicting medical undergraduates' willingness to work in PCPs ( $N=3020)(D O C X 17$ kb)

\section{Abbreviations \\ PCP: primary care provider; RN: registered nurse; MLE: maximum likelihood estimation; SD: standard deviation.}

\section{Competing interests}

The authors declare that they have no competing interests.

\section{Authors' contributions}

Under the guidance of $\mathrm{YK}, \mathrm{JH}$ and $\mathrm{MX}$ produced the first draft. JK and $\mathrm{AH}$ was involved in interpreting data and revising the manuscript critically. YK, ZD, and WW made substantial contributions to design of the study, acquisition of data, and revision of the manuscript. All authors read and approved the final manuscript.

\section{Acknowledgements}

Not applicable.

Funding

Not applicable.

\section{Author details}

${ }^{1}$ Institute of Medical Education, Peking University, Beijing, China. ${ }^{2}$ China Medical Tribune, Beijing, China. ${ }^{3}$ University of Michigan Medical School, Ann Arbor, MI, USA. ${ }^{4}$ Peking University Health Science Center, Beijing 100191, China.

Received: 17 July 2015 Accepted: 2 May 2016

Published online: 06 May 2016

\section{References}

1. National Health and Family Planning Commission of China. China Health and Family Planning Statistical Yearbook 2013. Beijing, China: Peking Union Medical College Press; 2013.

2. Long S. Primary care health professionals in rural China: current status, influential factors, and countermeasures. J Med Theory Pract. 2013;7:878-9.

3. Jiang Z, Wang S. Problems and countermeasures of rural health human resources in China. J Jiangxi TCM Univ. 2013;3:77-9.

4. Gu D, Zhang Z, Zeng Y. Access to healthcare services makes a difference in healthy longevity among older Chinese adults. Soc Sci \& Med. 2009;68(2):210-9. 
5. Martin I. Medical Workforce Development: Challenges and Opportunities for the Next 25 Years. Procedia Soc Behav Sci. 2010;2(5):6914-9.

6. Li L. Study on the problems and its countermeasures of prevention medicine education for clinical medical postgraduates. Chin J Med Educ 2011;31(1):135-6.

7. Chen D. Discussions on the current situation and development of primary care health professionals in rural China. J Anhui Health Vocat \& Tech Coll. 2012;6:1-2.

8. Chen L, Cai H, Yan S, et al. Study on issues and countermeasures regarding human resources of township health centers: questionnaire survey of 553 township health center directors in Fujian province. Chin Rural Health Serv Adminis. 2010;1:6-8.

9. Zhang $T$, Lin W, Wang $P$, et al. Analysis of human resources of township health centers in a prefecture. Guid Chin Med. 2012;2:277-8.

10. Zou M, Zhang G, Zhang J. Study on the current status of primary care health workforce in Ningbo city. Chin Rural Health Serv Adminis. 2013;6:610-3.

11. Zhou W. Primary care health professionals: current status, issues, and suggestions. Chin Gen Pract. 2010;7:685-8.

12. Xu D, Sun B, Wan X, et al. Reformation of medical education in China. Lancet. 2010;375(9725):1502-4.

13. Anand S, Fan VY, Zhang J, et al. China's human resources for health: quantity, quality, and distribution. Lancet. 2008:372(9651):1774-81.

14. Wang W, Xing $X$, Zhang $L$, et al. Study on 841 medical students' attitude toward future career. Soft Sci Health. 2007:3:220-1.

15. Li Y, Zhao H, Zhang E. Analysis on attitude toward employment of medical students in different grades. J Liaoning Med Univ (Soc Sci Ed). 2008;4:28-30.

16. Wang L, Zhang Y, Yang J, et al. Study on 3-year medical students' willingness to work in primary care entities. Chin Vocat Tech Educ. 2009;34:61-3.

17. Fang $Y$, Zheng $X$, Lin $Q$, et al. Thinking on the problem of grass -roots employment of clinical medical graduates. Chin Med Herald. 2013;23:166-8.

18. Zhu H, Zhao J, Wu H. Study on the current status of medical students' career preference. Chin Higher Med Educ. 2000;3:22-4.

19. Fang $Y$, Zheng $X$, Yuan $X$, et al. Study on countermeasures for medical students' employment in primary care givers. Chin Health Serv Manage. 2011:8:617-9.

20. Jiang P, Meng L, Liu Z. Study on the impact of medical students' career preference on their career decisions. J Qiqihar Med Coll. 2008;9:1094-6.

21. Liu $X$, Jiang $R$, Zhou $M$, et al. Survey and analysis of the first rural directional medical students' career planning. J Kunming Med Univ. 2011;11:43-6.

22. Yaisawarng $\mathrm{S}, \mathrm{Ng}$ YC. The impact of higher education reform on research performance of Chinese universities. Chin Econ Rev. 2014;31:94-105.

23. Ministry of Health of China, State Administration of Traditional Chinese Medicine of China, National Development and Reform Commission of China, Ministry of Finance of China. Development and construction plan for the health services system in rural areas. 2006. http://www.gov.cn/zwgk/ 2006-09/13/content_387186.htm. Accessed 15 Apr 2016.

24. Wang $H$, Chen $H$, Zhang $Y$, et al. Less than twenty percent of medical graduates volunteer to be employed in primary care entities according to a survey by Peking University Health Science Center. Chin Comm Doc. 2011;4:3-14.

25. Wei $Y$, Duan $Q$, Bao G, et al. Analysis on the human resource situation for health personnel in rural area of Jiangsu. Mod Prev Med. 2015;42(2):269-72.

26. Peng Y. Countermeasures for the stabilization of rural health manpower resources from the perspective of universal coverage. Chin Med Ethics. 2014;27(5):645-7.

27. Ren $S$, Liu L, Jiang $Q$, et al. An analysis of current situation and problems on Chinese rural health human resource. Chin Health Serv Manage. 2013;12:912-4

28. Zhao L. Human Resource Management in Grassroots Hospitals- Taking township Hospitals in Henan Province as Example [J]. Henan Sci. 2014;32(8):1679-82.

29. Wilson NW, Couper ID, De Vries E, et al. A critical review of interventions to redress the inequitable distribution of healthcare professionals to rural and remote areas. Rural Remote Health. 2009;9(2):1060.

30. Kletke PR, Marder WD, Silberger AB. The growing proportion of female physicians: implications for US physician supply. Am J Public Health. 1990;80(3):300-4.
31. Tian X, Wang J, Huang W, et al. Study on the employment orientation and the influencing factors of Guizhou medical students. Chin Health Serv Manage. 2014;2:137-9.

32. Huang $X$, Lin L, Wang $X$, et al. Analysis on medical students' willingness to work in primary care providers. Chin J Health Policy. 2014;8:46-50.

33. Yang $G$, Yan J. Survey of medical students' willingness to engage in primary health services. Chin Nurs Res. 2013;27(9B):2862-3.

34. Norington M. An update on rural general practice education initiatives to meet rural workforce needs: progress and recent developments. Aust J Rural Health. 1997;5(4):204-8

35. Verby JE. The Minnesota Rural Physician Redistribution Plan, 1971 to 1976. JAMA. 1977;238(9):960-4

36. Kamien $\mathrm{M}$, Buttfield $\mathrm{IH}$. Some solutions to the shortage of general practitioners in rural Australia. Part 1. Medical school selection. Med J Aust. 1990;153(2):105-7.

37. Rolfe IE, Pearson SA, O'Connell DL, et al. Finding solutions to the rural doctor shortage: the roles of selection versus undergraduate medical education at Newcastle. Aust N Z J Med. 1995;25(5):512-7.

38. National Development and Reform Commission of the People's Republic of China, Ministry of Health of the People's Republic of China, Ministry of Education of the People's Republic of China, Ministry of Finance of the People's Republic of China, Ministry of Human Resources and Social Security of the People's Republic of China. Implementation suggestions on targeted enrollment of tuition-free medical students for rural areas. 2010. http:// www.gov.cn/zwgk/2010-06/08/content_1623025.htm. Accessed 4 May 2015.

\section{Submit your next manuscript to BioMed Central and we will help you at every step:}

- We accept pre-submission inquiries

- Our selector tool helps you to find the most relevant journal

- We provide round the clock customer support

- Convenient online submission

- Thorough peer review

- Inclusion in PubMed and all major indexing services

- Maximum visibility for your research

Submit your manuscript at www.biomedcentral.com/submit

) Biomed Central 